\title{
ASSESSING ACCESSIBILITY OF URBAN GREEN SPACES BASED ON ISOCHRONE MAPS AND STREET RESOLUTION POPULATION DATA THROUGH THE EXAMPLE OF ZALAEGERSZEG, HUNGARY
}

\author{
Ronald András KOLCSÁR ${ }^{1 *}$ \& Péter SZILASSI ${ }^{2}$ \\ ${ }^{1}$ University of Szeged, Student, Faculty of Science and Informatics, 2-6 Egyetem Street, Szeged, Hungary, \\ e-mail: kolcsarrony@hotmail.com \\ ${ }^{2}$ University of Szeged, Department of Physical Geography and Geoinformatics, 2-6 Egyetem Street, Szeged, Hungary, \\ e-mail: toto@geo.u-szeged.hu
}

\begin{abstract}
As a result of the growing population and the increasing extremes of Urban Heat Island, the value of urban green spaces is getting more recognized. These green spaces - especially urban parks provide numerous ecosystem services to the local citizens creating a more livable environment. Many studies state that accessibility to these services has a key role in the realization of these positive effects, thus accessibility assessment has got more attention during the recent years in the field of ecosystem services. In this paper walking travel-time based isochrone maps and street resolution population data (number of local inhabitants) were used to estimate the number of city dwellers within the accessibility zones. This study is expected to provide a new method for measuring green space accessibility and help urban planners and decision makers understand the spatial differences between the various urban parks in a Hungarian case study area (Zalaegerszeg city).
\end{abstract}

Keywords: urban green spaces, accessibility, isochrone maps, population data, ecosystem services, Google Maps.

\section{INTRODUCTION}

According to numerous studies the increasing population, the urbanisation, the changes in patterns of human consumption, the planning policies, the socioeconomic conditions, the natural background, the infrastructure and the cultural or historical factors all have the potential to change the land-use and landcover (LULC) of periurban areas wich can easily lead to the fragmentation of habitats and the loss of biodiversity (Gavrilidis et al., 2015). Urban sprawl and the changes in LULC gradually drift away city dwellers from nature. To compensate this separation an ideal city has enough green spaces within its borders.

Urban parks and other green areas are important parts of urban ecosystems (Zhou \& Kim, 2013). Urban parks provide the city with various beneficial functions e.g. air quality improvement and effective $\mathrm{CO}_{2}$ absorption (Lee \& Hong, 2013; Reyes et al., 2014). Aside from these environmental effects, urban green spaces offer a great number of economic and also social benefits, like recreation, sport and other social activities (Zhou \& Kim, 2013; Reyes et al., 2014; Gupta et al., 2016). These benefits, that humans obtain, whether directly or indirectly, from ecosystems, are called ecosystem services (Millennium Assessment, 2005; Richards \& Friess, 2015; Ungaro et al., 2016; Ala-Hulkko et al., 2016; Zoderer et al., 2016).

To utilize the services provided by urban green spaces, potential users need a reasonable access to them (Reyes et al., 2014). These green areas are especially important for people with limited mobility or lack of possibility to enjoy private recreation e.g. young and senior citizens, people with low income or ethnic minority people (Rigolon, 2016). It is a question of great importance which is the biggest distance that still counts as a 'reasonable access'. A study verified that $100-300 \mathrm{~m}$ is a threshold after which the use of an area starts to decline rapidly (Ekkel \& de Vries, 2016). According to Gupta et al., (2016) a neighbourhood park or a community park can be a little further than 10-15 minutes by walk. A city level park may be accessed by motorised means 
within about an hour. The authors also stated that preference for walking time changes with the hierarchical levels. Lowest levels have a walking-time preference of 0-5 minutes. The maximum preferred walking time is about 10 minutes in a case of a neighbouring park and 15 minutes if the park is on a higher hierarchical level (e.g. community park).

For measuring accessibility, Geographic Information System (GIS) has been proven a useful tool (Kong \& Nakagoshi, 2006; Oh \& Jeong, 2007; Lee \& Hong, 2013; Gupta et al., 2016). Many researchers use linear buffering and network analysis to calculate the accessibility of an area (Comber et al., 2008; Gupta et al., 2016).

Authors of this paper aimed to make estimations - with the help of isochrone maps (interpolated from pedestrian travel times) and street resolution population data - about the accessibility of the green areas of Zalaegerszeg, Hungary. Our study has three questions: 1. How much time is needed from certain points of the town to reach the studied green areas. 2. How much time do locals need from certain points of the town to reach the closest green area? What is the number of local inhabitants who have the same walking travel time for given green areas?

\section{CASE STUDY AREAS}

The studied green areas of the present paper were four urban parks and a forest area within the municipality town of Zala county, Zalaegerszeg, Hungary, Central Europe. All of the selected green areas are bigger than 1 ha and presumably all five areas are able to provide a great portion of ecosystem services (walking, running, dog walking, etc.). Based on these criteria this paper focused on the following green spaces (Fig. 1). Vizslapark (V) has the greatest extension of the study areas (ca. 4.7 ha). It has an approximately equal amount of lawn and tree covered areas. $\mathrm{V}$ is close to the city centre and it is surrounded by a number of different types of buildings. Május 1 . liget (M) is one of the smallest (ca. $1.3 \mathrm{ha}$ ) and also the narrowest parks of Zalaegerszeg. The dendroflora of this park is roughly evenly distributed. Béke liget (Be) and Baross liget $(\mathrm{Ba})$ have very similar characteristics. Ba is the smallest park in the town (ca. $1 \mathrm{ha}$ ), Be has a slightly greater area (ca. $1.7 \mathrm{ha}$ ). Since they are adjacent areas their environment is very similar. These parks are located in the central part of Zalaegerszeg with significant traffic, hence they have a noise pollution above average. Parkerdö (P), unlike the other study areas is not an urban park, but a forest area.

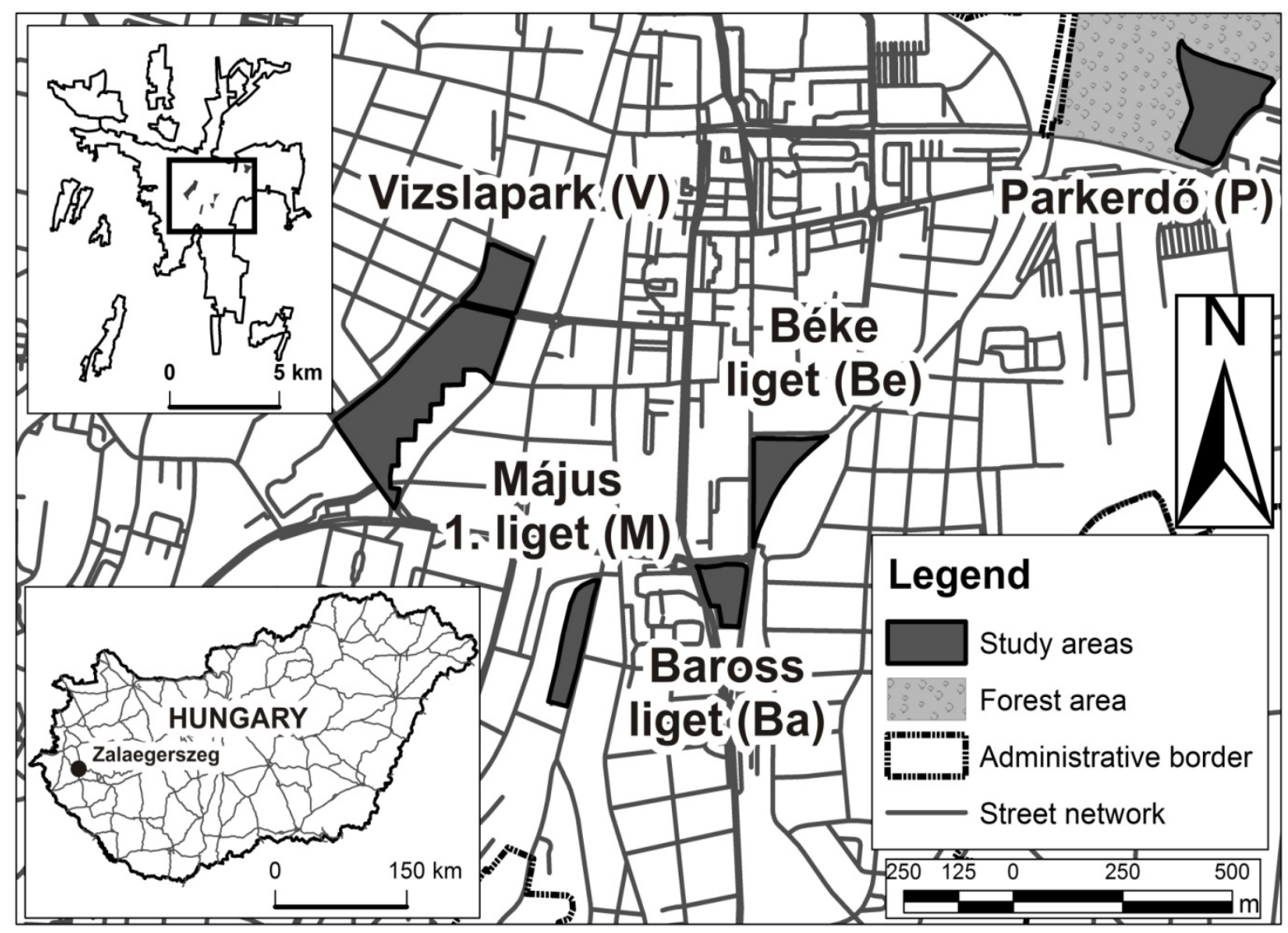

Figure 1. Geographical location of the study areas. 

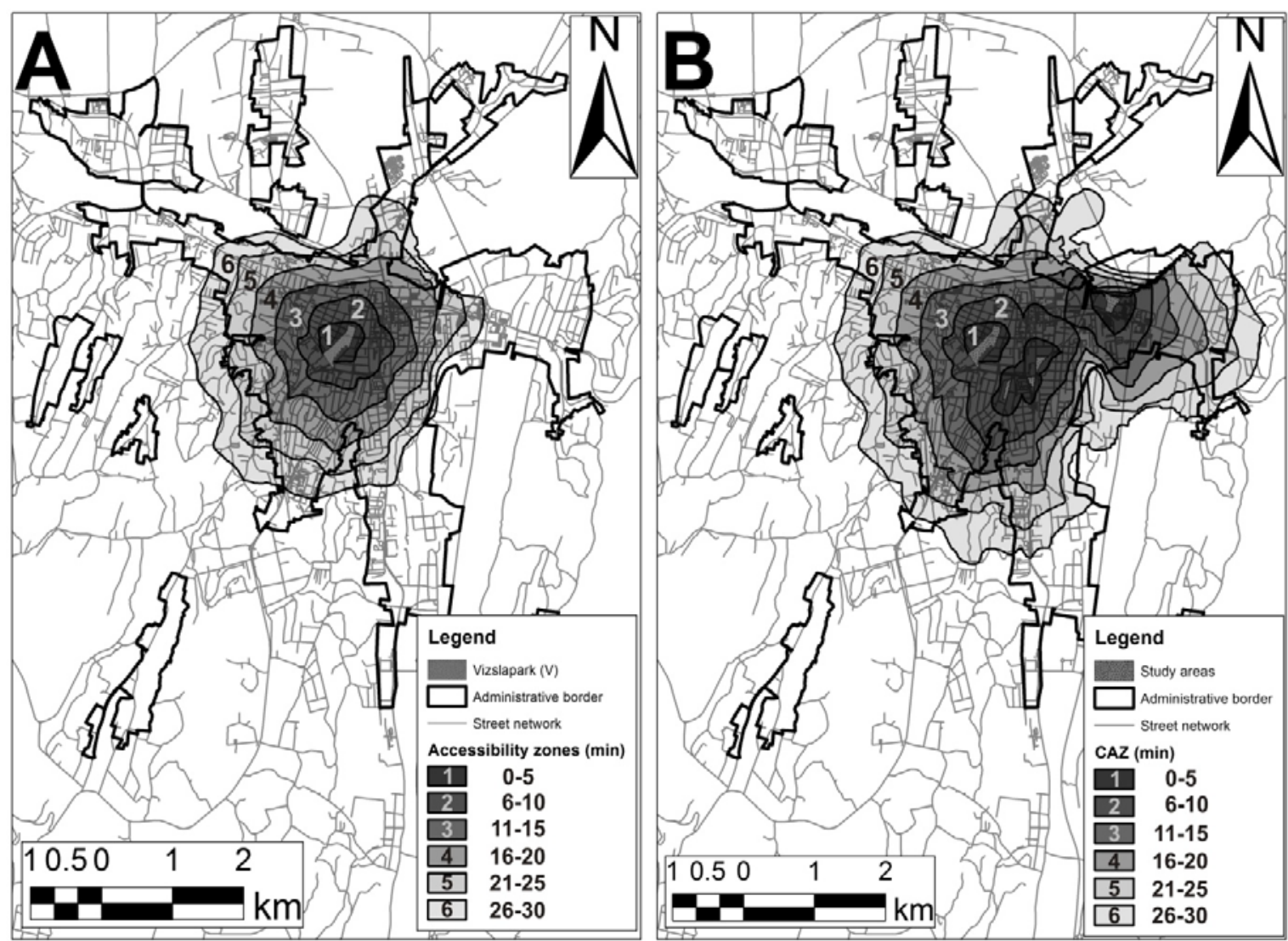

Figure 2. Isochrone map of the V study area (A) and the CAZ of the study areas (B)

In this study authors focused on a smaller part of this forest which has similar features to an urban park. $\mathrm{P}$ is situated in the urban fringe, and has a rich dendroflora. Its area is approximately $3.2 \mathrm{ha}$.

\section{MATERIALS AND METHODS}

In the first step to define the accessibility of each studied green area, isochrone maps were created based on the walking travel times (calculated in Google Maps) needed to reach the geometrical centre of the study areas from the randomly selected points of the town. Five of these maps represent the accessibility zones (isochrone zones) of the five green areas, separated from the others. The sixth one represents the Combined Accessibility Zones (CAZ) of all of the five areas. CAZ show the accessibility of the closest study area from every part of the town. After the intersection of these zones, with the street network containing the street resolution population data, authors were able to estimate the accessibility of the study areas.

\subsection{Delineation of isochrone maps}

The isochrone maps that the authors used for this study are based on the walking distances that one needs to overcome in order to reach the target green area from one's home. To create these maps, as the first step, the geometrical centre of each park was appointed. Secondly, 1000 random sample points were defined on the street network of the town within the administrative borders (both downtown and suburbs). Another 24 points were appointed outside the area of the city for the more accurate extrapolation. A pedestrian travel time by foot was calculated based on Google Maps walking route planner engine between each individual point and the geometrical centres of the parks. Google Maps route planner works with a 4.6 $\mathrm{km} / \mathrm{h}$ pedestrian (average) walking velocity and it calculates travel times accordingly. After the calculations an ordinal (12 points, spherical) kriging interpolation method was executed in ArcGIS 10. environment on the points to create a raster layer containing the pedestrian travel time on foot in every corner of the town. The 5-10-15-20-25 and 30 minutes walking time isochrones were vectorized around every park and 5 minute-wide accessibility zones were delineated. To facilitate the quantification isochrone zones were also assigned to a number from 1 to 6 . By intersecting the 5 isochrone maps of each case study areas (urban green areas) with each other a combined isochrone map was created (CAZ) (Fig. 2). This map shows how much walking time is needed to reach the 
closest green area on foot from the sample points of the town. The ArcGIS 10 software was used for this analysis.

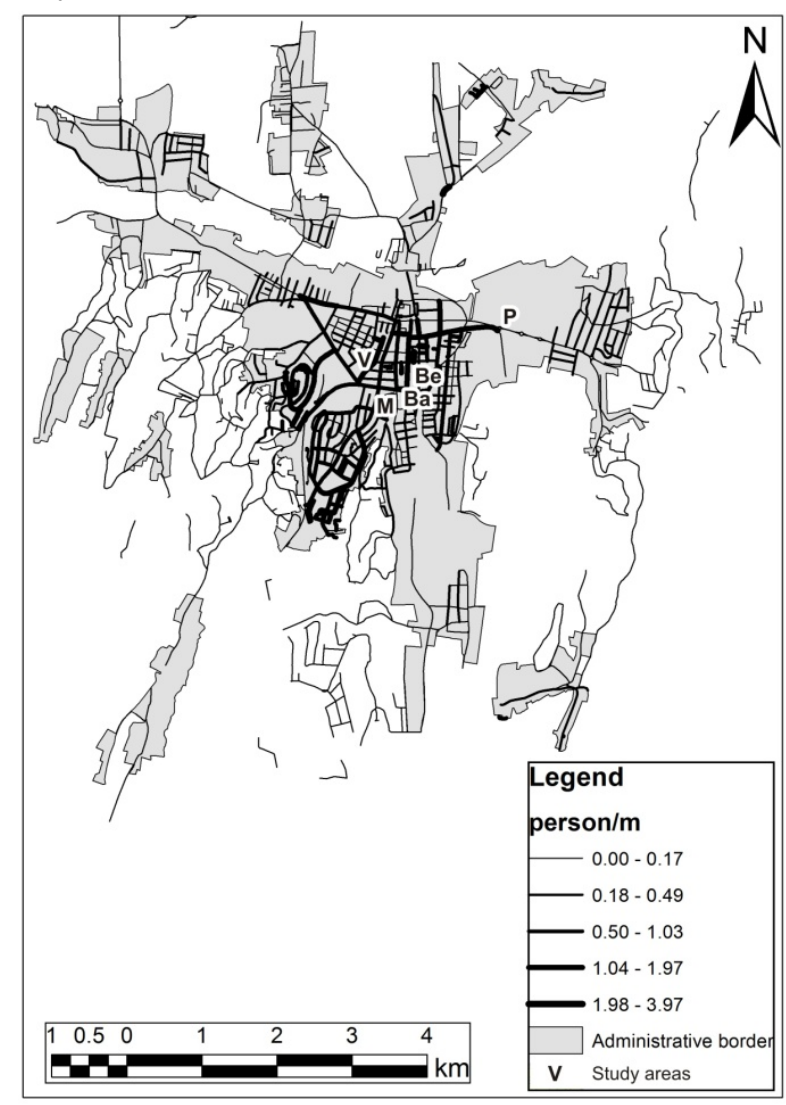

Figure 3. Street level density of local inhabitants (person/m) of Zalaegerszeg

\subsection{Overlaying street resolution average number of citizens and isochrone maps}

For the estimation of the number of city dwellers living inside the accessibility (isochrone) zones, we used the most detailed (street resolution) and most accurate (01.01.2016.) population data of the local inhabitants. This data provided by KEKKH (Central Office for Administrative and Electronic Public Services of Hungary) was spatially jointed with the OpenStreetMap road network of Zalaegerszeg (both downtown and suburbs) in ArcGIS 10. environment. Every street having no local citizen population at all was ignored from the analysis. As the next step, the average number of inhabitants/m was calculated for each street (Fig. 3). Afterwards the layer of the street network was intersected with the isochrone maps. Finally, the average population/meter was multiplied by the sum of the length of the streets within the zones. As a result, an approximate number of locals living inside these accessibility zones was estimated. By adding up the estimated number of inhabitants of the zones, the accessibility can be quantified. In this study, the first six isochrone zones were summed since we defined 30 minutes as the maximum value of acceptable walking time (Eq. (1)).

where:

$$
A=\sum_{i=1}^{n}\left[\overline{\left(\frac{p}{l}\right)} * L\right]_{i}
$$
A estimated number of inhabitants living inside $\mathrm{n}$ isochrone zones (accessibility) [capita]
$\mathrm{p} \quad$ number of inhabitants in given street [capita]
l l length of given street [m]
L full length of streets within given isochrone zone [m]
i number of the isochrone zone [1-6]

To determine the differences between the individual zones and the CAZ we calculated the ratio between these two according to the following formula (Eq. 2).

where:

$$
R_{x ; i}=\frac{a_{x ; i}}{a_{C A Z ; i}} * 100
$$

$$
\begin{array}{ll}
\mathrm{i} & \text { number of the isochrone zone [1-6] } \\
\mathrm{x} & \text { the examined strudy area [V, M, Ba, Be, P] } \\
\mathrm{R}_{\mathrm{x} ; \mathrm{i}} & \begin{array}{l}
\text { ratio between the estimated number of } \\
\text { people in the } \mathrm{i} \text { isochrone zone of } \mathrm{x} \text { study }
\end{array} \\
& \begin{array}{l}
\text { area and the i isochrone zone of the CAZ } \\
\text { [\%] }
\end{array} \\
\mathrm{a}_{\mathrm{x} ; \mathrm{i}} & \begin{array}{l}
\text { accessibility of } \mathrm{i} \text { isochrone zone in } \mathrm{x} \text { study } \\
\text { area [capita] } \\
\mathrm{a}_{\mathrm{CAZ} ; \mathrm{i}}
\end{array} \\
& \begin{array}{l}
\text { accessibility of } \mathrm{i} \text { isochrone zone in the CAZ } \\
\text { [capita] }
\end{array}
\end{array}
$$

\section{RESULTS AND DISCUSSION}

Results indicate that during the shortest walking time most people have access to $\mathbf{V}$ and $\mathbf{B e}$ study areas. With 10 minutes walking time, Be urban park has the accessibility for the most citizens. In a maximum of 30 minutes - with the exception of $1 \mathbf{p}$ every park is accessible to almost the same number of people. $\mathbf{M}$ city park has the most people inside its accessibility zones. The number of people living inside the accessibility zones of $\mathbf{V}$ and $\mathbf{B a}$ study areas is also significant. In the 5 minutes, 10 minutes and 15 minutes zones the number of people is the lowest in $\mathbf{P}$. As a result, in 30 minutes $\mathbf{P}$ is accessible almost half of the people compared to $\mathbf{M}$ (Fig. 4).

By comparing the study areas (urban parks) on figure 4, it becomes clear that the accessibilities of $\mathbf{V}$, $\mathbf{M}, \mathbf{B a}$ and $\mathbf{B e}$ are very similar. Since they are located close to each other, there are a great proportion of people who have good access to more than just one of them. As a consequence of peripheral location, $\mathbf{P}$ has the poorest accessibility amongst the study areas. Assuming people prefer the closest green space when deciding to visit one, the CAZ provide a more realistic picture about the green space accessibility in Zalaegerszeg. 


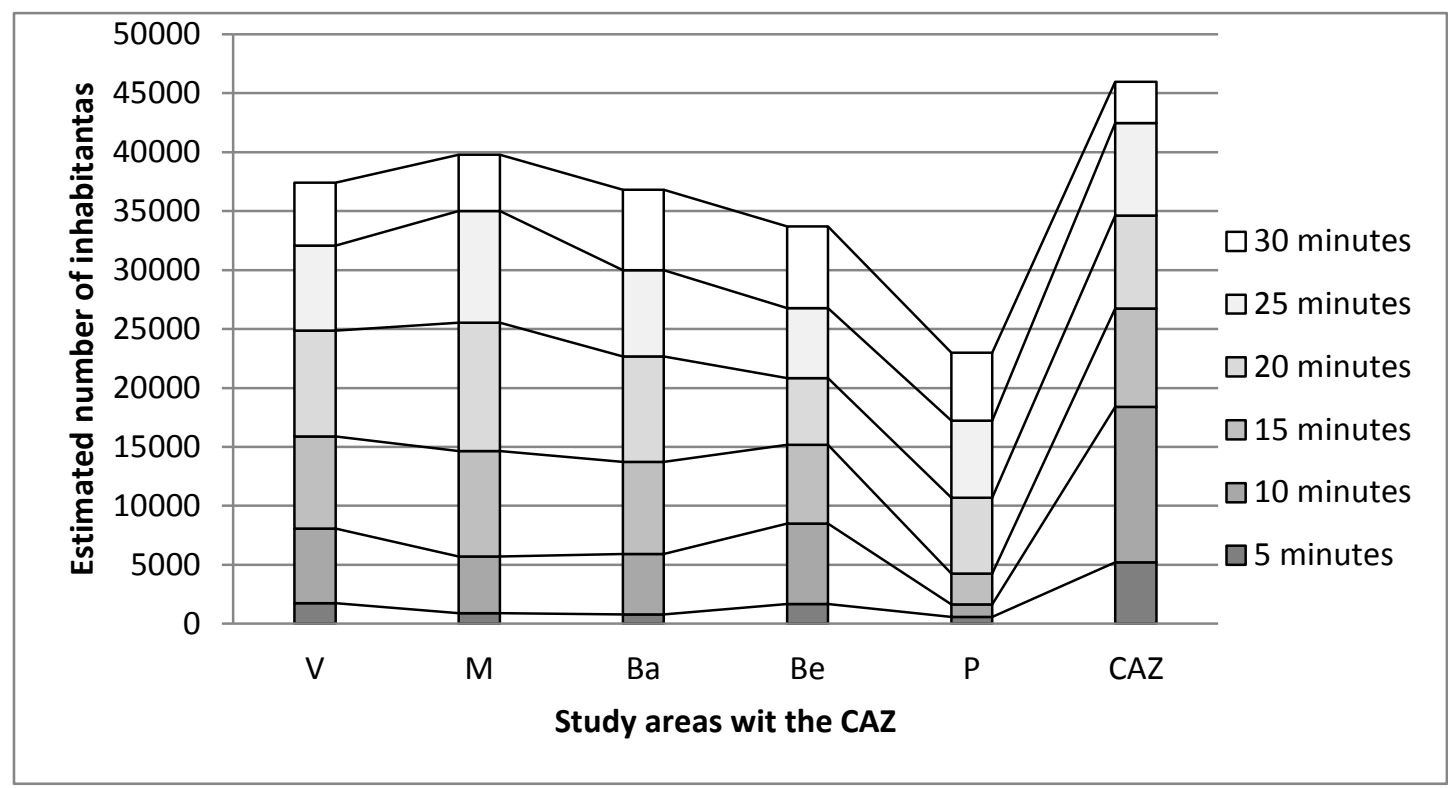

Figure 4. Estimated number of local inhabitants who have access to parks by foot within each accessibility zones

In figure 4 it can be seen that the CAZ contain only a slightly more individuals than the separate ones. The distribution of people inside these zones however indicates significant differences. These differences are caused by the relocation and the changed area of the accessibility zones. Combined 5 and 10 minutes zones contain more citizens because their areas are greater and both of them are located in the areas of Zalaegerszeg which have the highest population density. The 15, 20 and 25 minutes zones on the combined map have a similar number of people inside their areas than the same zones of the individual maps. This is because, on one hand 15-20-25 minutes CAZ are located on sparser parts of the town, but on the other hand the areas of the CAZ are bigger. While the first phenomenon has a negative, the second one has a positive effect on the number of people in the zones. The 30 minutes zone has half the number of people compared to the 30 minutes zones of the individual isochrone maps. The reason for this is that a huge part of that accessibility zone is located on the outskirts of the town. On these hilly areas there are a smaller number of residencies and a greater number of weekend houses. Figure 5 illustrates the rate of people inside the individual isochrone zones compared to the zones of the combined map $\left(\mathrm{R}_{\mathrm{x} ; \mathrm{i}}\right)$. If the $\mathrm{R}_{\mathrm{x} ; \mathrm{i}}$ value is equal to $100 \%$, the individual zone of given study area has the same estimated number of people than the same zone of the CAZ. $\mathrm{R}_{\mathrm{x}, \mathrm{i}}<100$ means that the estimated number of people in the individual accessibility zone is lower than the one in the CAZ.

\section{CONCLUSION}

In this study, the authors estimated the number of people who have access to the green spaces of Zalaegerszeg city within certain periods of times. For the estimation of the accessibility of urban parks we overlaid isochrone maps and street resolution population data with GIS methods. As a result, authors were able to compare the accessibility of the study green areas, their spatial inequalities, the differences between the accessibility zones, and they were also able to make estimation about the combined accessibility of these areas. With this method we managed to delineate the areas of the town with low accessibility. Results indicate that accessibilities of different parks from different accessibility zones have a heterogeneous spatial pattern. Time based accessibility is determined particularly by three factors: the street network of the settlement, the location of the park and the spatial distribution of the local inhabitants. Optimisation and improvement of the accessibility of green spaces should be an important task for urban planners. With the development of infrastructure and the ecosystems in a green space the supply of its services can be intensified. As a consequence there could be an increasing chance that residents from further accessibility zones would visit the green spaces. It is also recommended that the city create new green areas on areas with lower accessibility by planting trees on empty lots, establishing new parks and connecting them with the green infrastructure with newly created alleys.

\section{Acknowledgements}

The authors would like to thank to the Central Office for Administrative and Electronic Public Services, Hungary which provided the street resolution population data for Zalaegerszeg. 


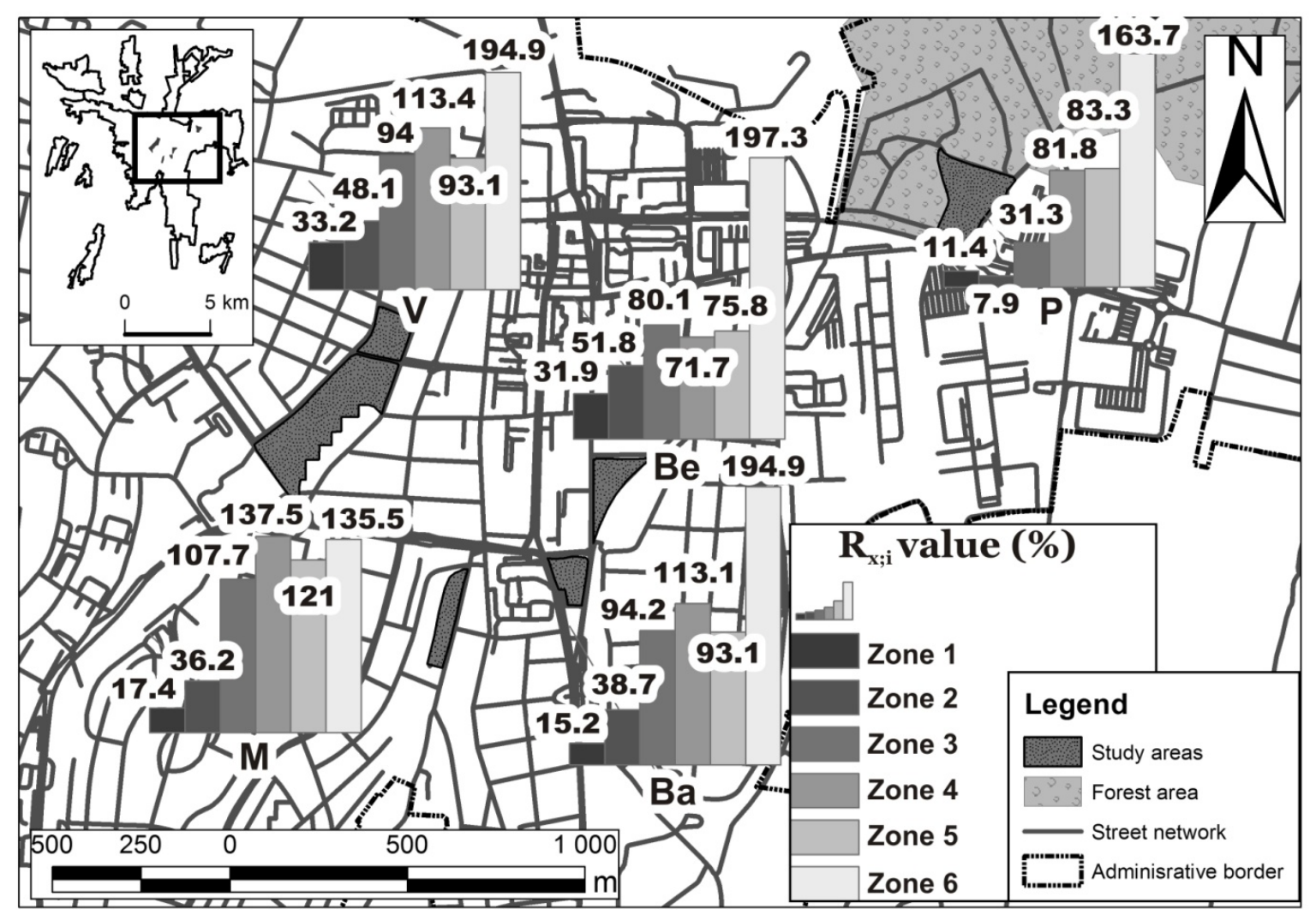

Figure 5. Estimated ratio of people who live in the separate accessibility zones to the people who live in the same zone of the CAZ.

\section{REFERENCES}

Ala-Hulkko, T., Kotavaara, O., Alahuhta, J., Helled, P. \& Hjort, J., 2016. Introducing accessibility analysis in mapping cultural ecosystem services. Ecological Indicators 66, 416-427

Comber, A., Brunsdon, C. \& Green, E., 2008. Using a GISbased network analysis to determine urban greenspace accessibility for different ethnic and religious groups. Landscape and Urban Planning 86, 103-114

Ekkel, E. D. \& de Vries, S., 2016. Nearby green space and human health: Evaluating accessibility metrics. Landscape and Urban Planning 157, 214-220

Gavrilidis, A. A., Grădinaru, S. R., Iojă, I. C., Cârstea, E. M. \& Pătru-Stupariu, I., 2015. Land use and land cover dynamics in the periurban area of an industrialized east-european city an overview of the last 100 years. Carpathian Journal of Earth and Environmental Sciences Vol. 10, No 4, p. 29 - 38

Gupta, K., Roya, A., Luthrac, K., Maithania, S. \& Mahavir, 2016. GIS based analysis for assessing the accessibility at hierarchical levels of urban green spaces. Urban Forestry \& Urban Greening 18, 198-211

Kong, F. \& Nakagoshi, N., 2006. Spatial-temporal gradient analysis of urban green spaces in Jinan, China. Landscape and Urban Planning 78, 147-164

Lee, G. \& Hong, I., 2013. Measuring spatial accessibility in the context of spatial disparity between demand and supply of urban park service. Landscape and Urban Planning 119, 85- 90

Received at: 17. 01. 2017

Revised at: 23. 05. 2017
Millennium Assessment, 2005. Ecosystems and human wellbeing: Synthesis (Millennium Ecosystem Assessment). Island Press, World Resources Institute Washington, D.C., USA.

Oh, K. \& Jeong, S., 2007. Assessing the spatial distribution of urban parks using GIS. Landscape and Urban Planning 82, 25-32

Reyes, M., Páez, A. \& Morency, C., 2014. Walking accessibility to urban parks by children: A case study of Montreal. Landscape and Urban Planning 125, 38-47

Richards, D. E. \& Friess, D. A., 2015 A rapid indicator of cultural ecosystem service usage at a fine spatial scale: Content analysis of social media photographs. Ecological Indicators 53, 187-195

Rigolon, A., 2016. A complex landscape of inequity in access to urban parks: A literature review. Landscape and Urban Planning 153, 160-169

Ungaro, F., Häfner, K., Zasada, I. \& Piorr, A., 2016. Mapping cultural ecosystem services: Connecting visual landscape quality to cost estimations for enhanced services provision. Land Use Policy 54, 399-412

Zhou, X. \& Kim, J., 2013. Social disparities in tree canopy and park accessibility: A case study of six cities in Illinois using GIS and remote sensing. Urban Forestry \& Urban Greening 12, 88-97

Zoderer, B. M., Tasser, E., Erb, K., Stanghellini, P. S. L. \& Tappeiner, U., 2016. Identifying and mapping the tourists' perception of cultural ecosystem services: A case study from an Alpine region. Land Use Policy 56, 251-261

Accepted for publication at: 29. 05. 2017 Published online at: 06.06. 2017 